\title{
Ethanol/gasoline droplet heating and evaporation: effects of fuel blends and ambient conditions
}

\author{
Mansour Al Qubeissia, ${ }^{\mathrm{a},{ }^{*}}$, Nawar H.I. Al-Esawia, Sergei S. Sazhinc, M. Ghaleeh ${ }^{\mathrm{b}}$ \\ anstitute for Future Transport and Cities, Coventry University, Coventry CV1 5FB, United Kingdom \\ ${ }^{b}$ School of Mechanical, Aerospace and Automotive Engineering, Faculty of Engineering, Environment and \\ Computing, Coventry University, Coventry CV1 2JH, United Kingdom \\ cAdvanced Engineering Centre, School of Computing, Engineering, and Mathematics, University of Brighton, \\ Brighton BN2 4GJ, United Kingdom
}

\begin{abstract}
This paper focuses on the modelling of blended ethanol/gasoline fuel droplet heating and evaporation in conditions representative of internal combustion engines. The effects of ambient conditions (ambient pressure, ambient temperature and radiative temperature), and ethanol/gasoline fuel blend ratios on multi-component fuel droplet heating and evaporation are investigated using the analytical solutions to the heat transfer and species diffusion equations. The ambient pressures, gas and radiative temperatures, and ethanol/gasoline fuel ratios are considered in the ranges 3-30 bar, 400-650 K, 1000-2000 K, and 0\% (pure gasoline)-100\% (pure ethanol), respectively. Transient diffusion of 21 hydrocarbons, temperature gradient, and recirculation inside droplets are accounted for using the Discrete Component Model (DCM). The droplet lifetimes of all mixtures decrease at high ambient temperatures $(>400 \mathrm{~K})$, under all ambient pressures (3-30 bar). The combination of ethanol and gasoline fuels has a noticeable impact on droplet heating and evaporation; for pure ethanol, the predicted droplet surface temperature is $33.9 \%$ lower, and lifetime $24.3 \%$ higher, than that for gasoline fuel under the same conditions. Finally, taking into account radiation increases the gasoline fuel droplet evaporation times by up to $28.6 \%$, and those of ethanol fuel droplets by up to $21.8 \%$, compared to the cases where radiation is ignored.
\end{abstract}

Keywords: Droplet; Fuel blends; Gasoline; Ethanol; Heating and evaporation; Multi-component droplets.

*Corresponding author, email Mansour.Qubeissi@Coventry.ac.uk, tel. +44 (0)2477 4658060

\section{Introduction}

Many investigations have focused on the replacement of gasoline with ethanol/gasoline blends. These have been driven mainly by the importance of reducing greenhouse emissions and fossil fuel costs. ${ }^{1-3}$ According to the US environment protection agency, ${ }^{4}$ all gasoline engine vehicles can use a blend of gasoline fuel with up to $10 \%$ volume fraction of ethanol without the need for engine modification. The reduction in $\mathrm{CO}_{2}$ emissions without loss of engine performance is non-trivial for this mixture ${ }^{5}$. Mixtures with up to $15 \%$ volume fraction of ethanol and 
85\% volume fraction of gasoline fuel have been approved for use in 2001 and newer vehicles, under the US federal standards for renewable fuel; ${ }^{6}$ while mixtures with up to $85 \%$ volume fraction of ethanol and $15 \%$ volume fraction of gasoline fuel (i.e. flex fuels) have been defined as qualifying alternative fuels for flex-fuel vehicles. ${ }^{4}$ Therefore, it is important to investigate the difference in droplet lifetimes between ethanol and gasoline fuels, and their blends. Also, understanding the influence of ambient temperature on the evaporation of ethanol/iso-octane droplets is essential.7 Likewise, the influence of ambient pressure on the evaporation of a gasoline fuel and its surrogates is important in internal combustion processes. ${ }^{8}$ The impacts of ethanol/gasoline fraction on droplet evaporation and related combustion processes have recently been investigated numerically and experimentally (e.g. ${ }^{1-3}$ ) although without focusing on in-cylinder conditions.

In many studies, gasoline fuels are approximated by iso-octane (e.g. ${ }^{2,9-11}$ ), whilst in reality commercial gasoline fuels consist of tens of hydrocarbons.12 Multi-component fuel droplet heating and evaporation are essential processes in internal combustion engines, which strongly depend on ambient (in-cylinder) conditions and controlled spray combustion behaviour. The Discrete Component (DC) model, based on the analytical solutions to the heat transfer and species diffusion equations, suggested in, ${ }^{13-16}$ has been verified against the results of numerical solutions to these equations and validated against experimental data in. ${ }^{17}$ The effects of fuel compositions, transient diffusion of species, temperature gradient, and recirculation inside moving droplets on their heat balance and evaporation are commonly described in the DC model, using the Effective Thermal Conductivity/Effective Diffusivity (ETC/ED) model. ${ }^{13,18,19}$ Alternative approaches rely on probabilistic analyses of a large number of components (continuous thermodynamics ${ }^{20-22}$ and the distillation curve ${ }^{23-25}$ models). These approaches rely on several simplifying assumptions; for example, the species inside droplets are assumed to mix infinitely quickly (infinite diffusivity/infinite thermal conductivity (ID/ITC) model), or not to mix at all (single component (SC) model). Detailed comparisons of predictions of various models are presented in.19,26

Our study focuses on the effects of ambient pressure, ambient and radiative temperatures, and blending ratios on the evaporation characteristics of ethanol/gasoline fuel droplets. The previously developed version of the DC model is applied to the analysis of heating and evaporation of gasoline FACE C ffuel used in advanced combustion engines, type C) and ethanol droplets and their blends. The main features of the model are presented in Section 2. The results of our investigation into the impacts of fuel blends and ambient conditions on the time evolution of droplet temperatures and radii, and a validation of the model are presented in Section 3. The main results of the paper are summarised in Section 4. 


\section{Model}

As in,19,26,27 our analysis is based on the previously developed model, using the analytical solutions to the heat transfer and species diffusion equations in droplets, assuming spherically symmetric processes. The effects of droplet relative motion are accounted for using the Effective Thermal Conductivity/Effective Diffusivity (ETC/ED) model.

In contrast to, ${ }^{17-19,26}$ we have taken into consideration both the convective and radiative heating of automotive droplets. A more rigorous approach to modelling the radiative heating of droplets would take into account the semi-transparency of droplets as described in.15 This approach, however, would involve measurement of the absorption properties of gasoline and ethanol fuel components in the visible and infrared ranges which is currently not available. Our approach is based on the estimation of the maximal possible radiative absorption in droplets, which allows us to use a simplified model of the process.

In our approach, the droplet is assumed to be opaque and non-reflective (emissivity equal to 1). The following boundary condition is applied at its surface:

$\left.k_{\mathrm{eff}} \frac{\partial T}{\partial R}\right|_{R=R_{d}}=\rho L \frac{d R_{d}}{d t}+h\left(T_{g}-T_{s}\right)+\sigma T_{\mathrm{rad}}^{4}$

where $k_{\text {eff }}=\chi k_{l}$ is the effective thermal conductivity, $k_{l}$ is the liquid thermal conductivity, $\chi$ is the circulation coefficient (see ${ }^{13}$ for details), $\rho$ is the liquid density, $L$ is the latent heat of evaporation, $\frac{d R_{d}}{d t}$ is the rate of droplet radius change due to evaporation, $h$ is the convection heat transfer coefficient, $T_{g}$ is the ambient temperature, and $\sigma=5.670310^{-8} \mathrm{~W} \mathrm{~m}^{-2} \mathrm{~K}^{-4}$ is the Stefan-Boltzmann constant. The radiative temperature $T_{\text {rad }}$ is equal to gas temperature in the case of optically thick gas and external temperature in the case of optically thin gas. Our analysis will focus on the latter case when the impact of thermal radiation is expected to be the strongest for engine conditions.

The radiation flux emitted by the droplet $\sigma T_{d}^{4}$ to the ambient gas is assumed to be negligible, compared with the radiation flux hitting the droplet $\sigma T_{\text {rad }}^{4}$ (e.g. due to remote flames). The effect of radiation is considered within the analytical solution to the heat transfer equation, described in, ${ }^{13,16,19}$ by replacing the gas temperature with the effective temperature:

$$
T_{\text {eff }}=T_{g}+\frac{\rho L \frac{d R_{d}}{d t}}{h}+\frac{\sigma T_{\text {rad }}^{4}}{h} .
$$

The diffusion coefficient for the ethanol/gasoline blended-fuel vapour is estimated using the Sanchez-Clifton approach: ${ }^{28}$

$D_{\text {mix }}=x_{\text {oct }} D_{\text {oct }}+x_{\text {eth }} D_{\text {eth }}$ 
where $x_{\text {oct }}$ and $x_{\text {eth }}$ are the molar fractions of fuels, and the binary diffusion coefficients of iso-octane and ethanol vapours in air, estimated as: ${ }^{29}$

$D_{\text {oct }}=\left(-5.7810^{-2}+3.045510^{-4} T+3.426510^{-7} T^{2}\right) / p\left(\mathrm{~m}^{2} \mathrm{~s}^{-1}\right)$,

$D_{\text {eth }}=\left(-5.8910^{-2}+3.661510^{-4} T+7.629910^{-7} T^{2}\right) / p\left(\mathrm{~m}^{2} \mathrm{~s}^{-1}\right)$,

where $p$ is ambient pressure (in bar). Note that the original equations for the diffusion coefficients are presented in ${ }^{29}$ for $p=1$ bar.

As in, ${ }^{18,26,30}$ the diffusion coefficient of species in the liquid phase is estimated using the Wilke-Chang approximation:

$D_{l}=\frac{7.4 \times 10^{-15} T \sqrt{\bar{M}}}{\mu_{l} V_{v}^{0.6}}$,

where $\bar{M}$ is the average molar mass (in $\frac{\mathrm{kg}}{\mathrm{kmole}}$ ) of all components accounting for their mass fractions at the surface of the droplet, $V_{v}=\left(\sigma_{L J} / 1.18\right)^{3}$ is the effective potential, inferred from, 18,19 and $\sigma_{L J}=1.468 \bar{M}^{0.297}$ is the Lennard-Jones length scale (in $\AA$ ), inferred from. .8,31 $^{18,}$

The calculation of the saturated vapour pressure is discussed in Appendix A. All other thermodynamic and transport properties for gasoline fuel are inferred from. ${ }^{26}$ The thermodynamic and transport properties of ethanol are mainly inferred from..$^{32,33}$ The results of calculations of liquid ethanol density, heat capacity and thermal conductivity are compared in Appendix B. The latent heat of evaporation $(L)$ and saturated vapour pressure are calculated at droplet surface temperatures $T_{s}$, and all other liquid thermodynamic and transport properties are calculated at the average droplet temperature. All gas properties in the vicinity of a droplet are calculated at the reference temperature $\left(T_{\text {ref }}=\frac{2}{3} T_{\mathrm{S}}+\frac{1}{3} T_{\mathrm{g}}\right)$. The droplet impact on the ambient gas is ignored. The ambient air density is calculated using the ideal gas law. The analysis presented in this paper is based on the one-dimensional numerical discretisation of spherical droplet volume into 300 concentric layers within the liquid phase. The time step is set to $10^{-6} \mathrm{~s}$ (see ${ }^{19,34}$ for further details).

\section{Results}

\subsection{Model validation}

The results of application of the DC model to the evaporation of an ethanol/gasoline (combined iso-octane and heptane) mixture droplet were validated for mixtures EW30, EW70, and EW100 (EWX refers to a mixture with $\mathrm{X} \%$ weight fraction of ethanol and $(100-\mathrm{X}) \%$ weight fraction of gasoline) against experimental data inferred from. ${ }^{3}$ The results are shown in Figure 1. The mixtures of weight fractions EW30 and EW70 are approximately equivalent to the mixtures of volume fractions $27 \%$ ethanol/73\% gasoline and $67 \%$ ethanol/33\% 
gasoline, respectively. Droplets of $23.6 \mu \mathrm{m}$ initial radius and $280.15 \mathrm{~K}$ initial temperature were suspended in stationary dry air at 1 atm.

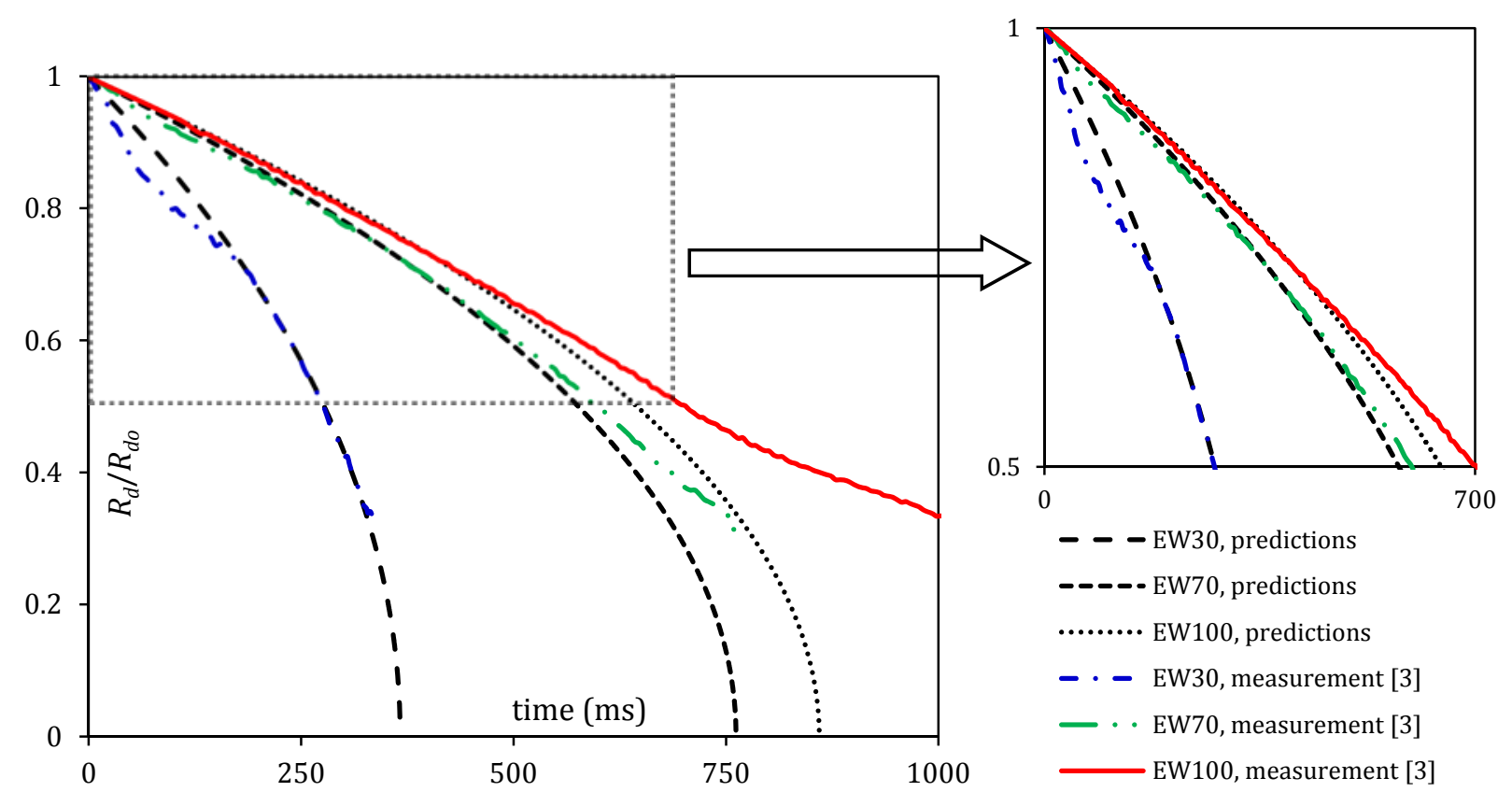

Figure 1. Predicted and experimentally measured ${ }^{3}$ normalised radii of the EW30, EW70 and EW100 droplets.

As can be seen from Figure 1, the predicted initial evolutions of droplet radii are close to those inferred from experimental data. However, clear deviations between model predictions and experimental data can be seen at the final stages of droplet evaporation. This deviation is attributed to the experimental procedure used in. ${ }^{3}$ As noted by the authors of, 3 this is caused by the water uptake from the ambient gas into fuel droplet during the measurement, the impact of which is outside the scope of our model. The impact of such measurement uncertainty becomes more significant for higher fractions of ethanol, hence experimental results near the end of EW70 - EW100 droplet evaporations are not reliable.

\subsection{Ethanol/gasoline fuel blends}

In the following analysis, the effects on droplet heating and evaporation on various molar fractions of ethanol in the mixture are investigated. The following molar fractions of ethanol are considered: $100 \%, 85 \%$, 50\%, 20\%, 5\% and 0\%. The corresponding molar mixtures are referred to as EM100, EM85, EM50, EM20, EM5 and EM0 as in the case when volume fractions of ethanol were considered. In this case, mixtures EM85, EM50, EM20 and EM5, are approximately equivalent to the mixtures with volume fractions 70\% ethanol/30\% gasoline, 29\% ethanol/71\% gasoline, 9\% ethanol/91\% gasoline, and 2\% ethanol/98\% gasoline, respectively. The plots of droplet surface temperatures $T_{s}$ and radii $R_{d}$ versus time for various ethanol/gasoline fuel blends, taking into account the contributions of all 21 components in gasoline fuel, are shown in Figures 2 and 3, respectively. As 
in, ${ }^{26}$ the initial droplet radius is taken equal to $R_{d o}=12 \mu \mathrm{m}$, and its constant axial velocity in still air and initial temperature are assumed equal to $U_{d}=24 \mathrm{~m} / \mathrm{s}$ and $T_{d o}=296 \mathrm{~K}$, respectively. The ambient air pressure and temperature are assumed constant and equal to $p_{g}=9$ bar and $T_{g}=545 \mathrm{~K}$, respectively.

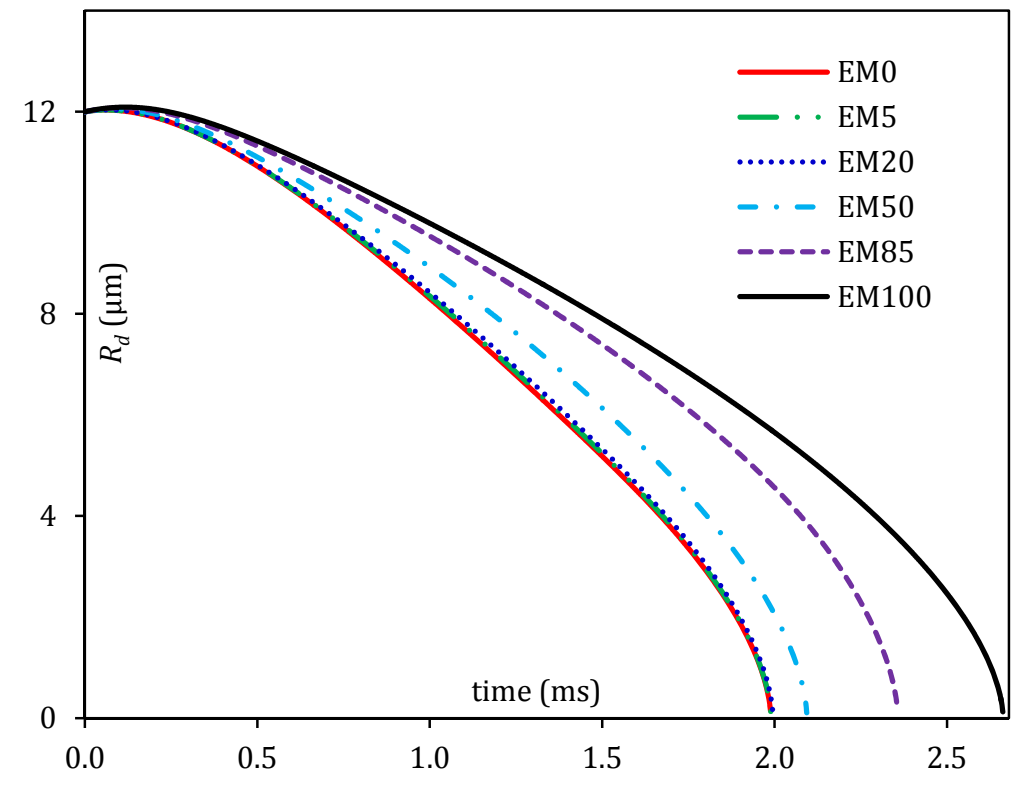

Figure 2. The plots of droplet radii $R_{d}$ versus time for various ethanol/gasoline blends. The droplet with the initial radius $12 \mu \mathrm{m}$ and initial homogeneous temperature $296 \mathrm{~K}$ is assumed to be moving with constant velocity $24 \mathrm{~m} / \mathrm{s}$ in still air. Ambient pressure and temperature are taken equal to 9 bar and $545 \mathrm{~K}$, respectively.

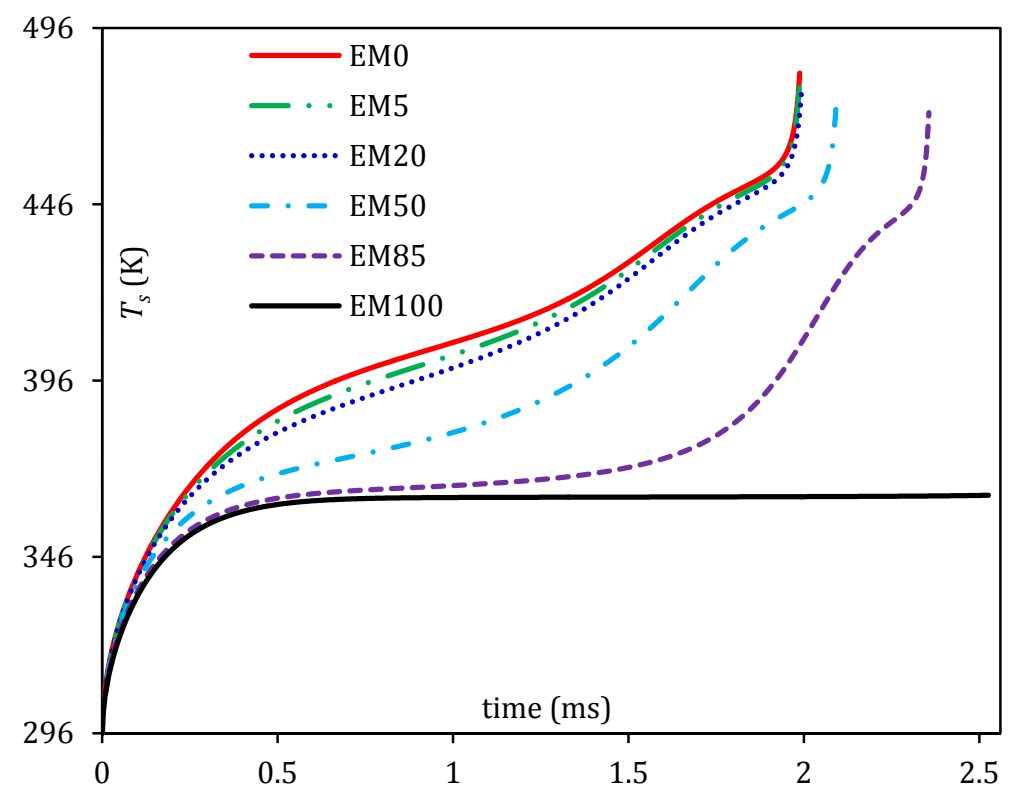

Figure 3. The plots of droplet surface temperatures $T_{s}$ versus time for various ethanol/gasoline blends for the same ambient conditions and input parameters as in Figure 2.

The plots for droplet radii and surface temperatures are shown for six blends of ethanol/gasoline fuel (EM0-EM100). The impact of ethanol/gasoline fuel blends on droplet lifetimes, compared to the case of pure gasoline FACE C fuel (EM0), is shown in Table 1.

Table 1. The impact of ethanol/gasoline fuel blends on estimated droplet lifetimes; 
Diff $^{*}=\frac{\text { lifetime(blend)-lifetime(E0) }}{\text { lifetime(E0) }} \times 100 \%$

\begin{tabular}{ccc}
\hline Blend & $\begin{array}{c}\text { Lifetime } \\
(\mathrm{ms})\end{array}$ & Diff*\% \\
\hline EM0 & 1.988 & - \\
EM5 & 1.989 & 0.050 \\
EM20 & 1.994 & 0.302 \\
EM50 & 2.093 & 5.282 \\
EM85 & 2.356 & 18.511 \\
EM100 & 2.662 & 33.903
\end{tabular}

As follows from Figure 2, the droplet lifetime for pure gasoline fuel (EM0) is shorter than for any of the blends. It increases as the fraction of ethanol increases. This trend is similar to that reported in.1,3 The difference reaches 33.9\% for EM100. This can be attributed to the different thermodynamic and transport properties of ethanol and gasoline; for example, the saturated vapour pressure and latent heat of evaporation of ethanol are much higher than those of averaged gasoline fuel components. In Figure 3, the predicted droplet surface temperature for EM100 is up to $24.3 \%$ higher than that predicted for EM0. The boiling and critical temperatures of ethanol (351.5 K and $514 \mathrm{~K}$, respectively) are lower, however, than those of gasoline components (e.g. for $\mathrm{C}_{8} \mathrm{H}_{18}$, these temperatures are $372.4 \mathrm{~K}$ and $543.9 \mathrm{~K}$, respectively), which leads to a lower droplet wet bulb surface temperature for the blends compared with the pure gasoline fuel. The time evolution of surface mass fractions of representative components of the fuel mixture is shown in Figure 4.

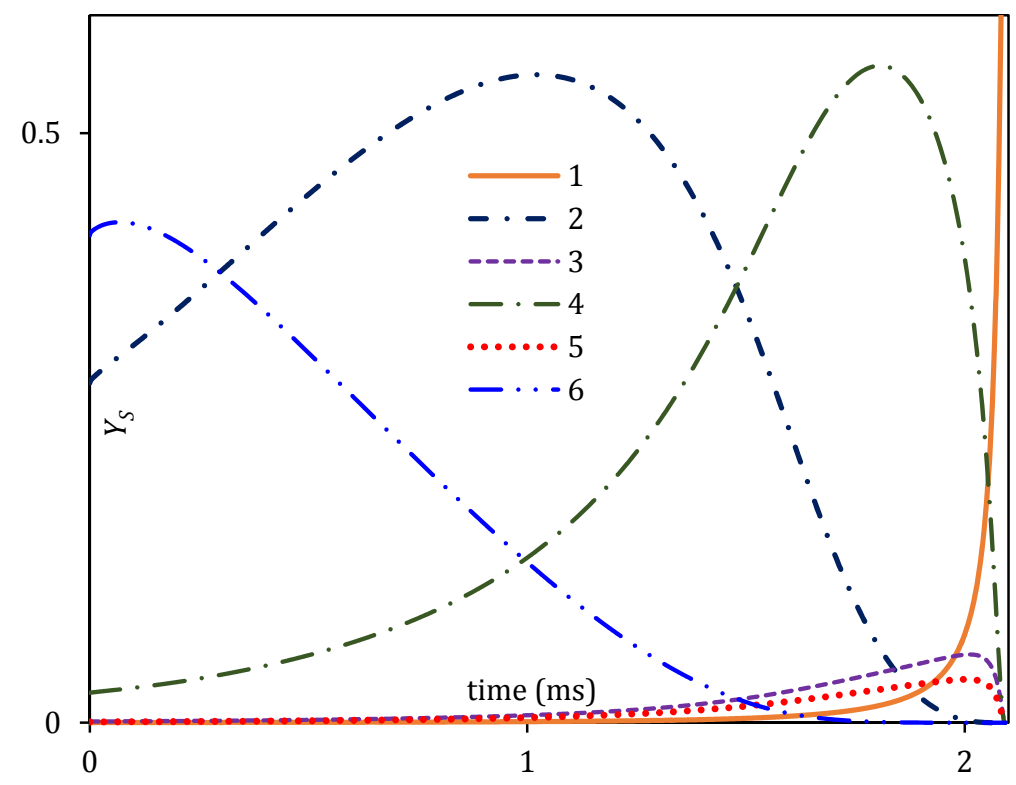

Figure 4. The plots of surface mass fractions of representative components of EM50, $Y_{s}$, versus time. The plots of the following components are shown: $n-\mathrm{C}_{12} \mathrm{H}_{26}$ (1), iso- $\mathrm{C}_{8} \mathrm{H}_{18}$ (2), iso- $\mathrm{C}_{11} \mathrm{H}_{24}$ (3), $\mathrm{C}_{9} \mathrm{H}_{12}(4), \mathrm{C}_{9} \mathrm{H}_{10}(5)$ and $\mathrm{C}_{2} \mathrm{H}_{6} \mathrm{O}$ (6). The same ambient conditions and input parameters as in Figures 2 and 3 have been used.

As follows from Figure 4, the mass fractions of heavy components monotonically increase with time at the expense of lighter components. The mass fractions of the intermediate components (iso- $\mathrm{C}_{8} \mathrm{H}_{18}$ ) initially increase but then decrease with time. This is consistent with the results of our previous studies of this phenomenon. ${ }^{15}$ 
One can expect this complex behaviour of different components to affect the distributions of mass fractions of components inside the combustion chamber in realistic engine-like conditions, where the ambient gas temperatures are not homogeneous.

\subsection{Impact of ambient conditions}

As mentioned earlier, in contrast to previous studies (e.g. ${ }^{35,36}$ ), our model takes into account the impact of thermal radiation on droplet heating. The focus is on a reasonable range of petrol engine injection conditions, accounting for different radiative temperatures and in-cylinder pressures and temperatures for EM0-EM100 fuel mixtures. The results are presented in Figures 5-9.

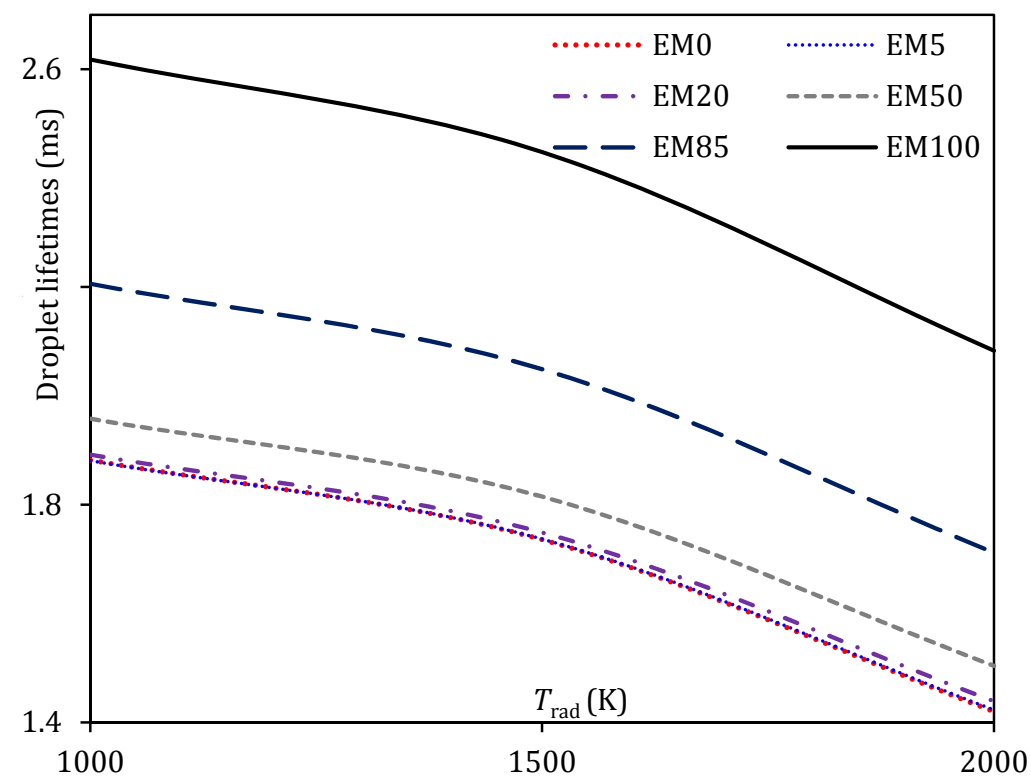

Figure 5. The estimated droplet lifetimes versus radiative temperatures $T_{\text {rad }}$ for EM0-EM100 fuel blends, using the DC model and the same input parameters as in Figures 2-4. The differences between these predictions are shown in Table 2.

Table 2. The blended fuel droplet lifetimes when the effects of thermal radiation are taken into account and the estimated differences compared with the predictions of the model when radiation is ignored (Table 1), as inferred from Figure 5 and Appendix C (Diff $\%=\frac{\text { time }_{\text {no rad }}-\text { time }_{\mathrm{w} / \mathrm{rad}}}{\text { time }_{\text {no rad }}}$ ).

\begin{tabular}{c|cc|cc|cc}
\hline \multirow{2}{*}{ Blends } & \multicolumn{2}{|c|}{$T_{\text {rad }}=1000 \mathrm{~K}$} & \multicolumn{2}{c|}{$T_{\text {rad }}=1500 \mathrm{~K}$} & \multicolumn{2}{c}{$T_{\text {rad }}=2000 \mathrm{~K}$} \\
& time $(\mathrm{ms})$ & Diff $\%$ & time $(\mathrm{ms})$ & Diff $\%$ & time $(\mathrm{ms})$ & Diff \% \\
\hline E0 & 1.882 & 5.33 & 1.736 & 12.67 & 1.42 & 28.57 \\
E5 & 1.881 & 5.43 & 1.737 & 12.67 & 1.423 & 28.46 \\
E20 & 1.892 & 5.11 & 1.749 & 12.29 & 1.439 & 27.83 \\
E50 & 1.958 & 6.45 & 1.815 & 13.28 & 1.504 & 28.14 \\
E85 & 2.206 & 6.37 & 2.049 & 13.03 & 1.712 & 27.33 \\
E100 & 2.618 & 1.65 & 2.448 & 8.04 & 2.083 & 21.75
\end{tabular}

As follows from Figure 5, the potential for radiation to reduce droplet lifetimes becomes more significant at higher radiative temperatures, as expected. Further illustrations of this effect are presented in Appendix C. 


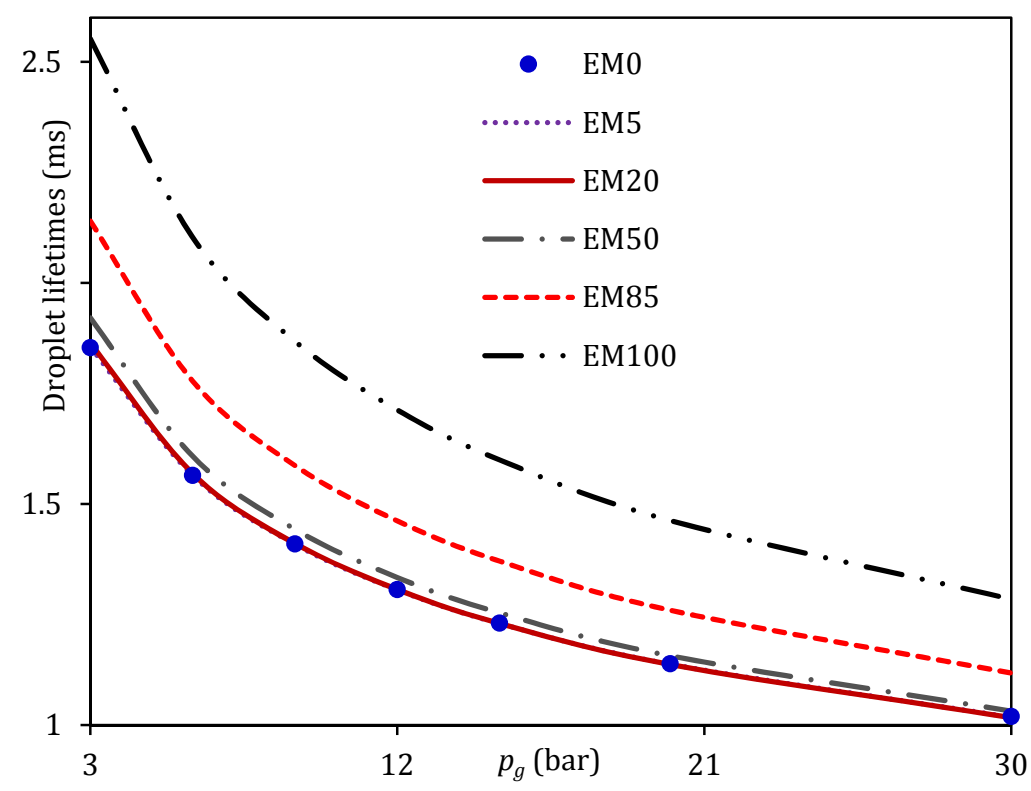

Figure 6. The effect of ambient pressures on droplet lifetimes for EM0-EM100 fuel blends, estimated at ambient gas temperature $650 \mathrm{~K}$, using the DC model and the same other input parameters as in Figures 2-5; the effects of thermal radiation are ignored.

As shown in Figure 6, increasing the ambient pressure at a relatively high ambient temperature (650 K) leads to a reduction in estimated droplet lifetimes with almost the same effect for all mixtures (EM0-EM100, with higher droplet lifetimes for EM100 and lower ones for EM0). Similar trends are observed when ambient temperatures are increased at a relatively low ambient pressure (3 bar) (see Figure 7).

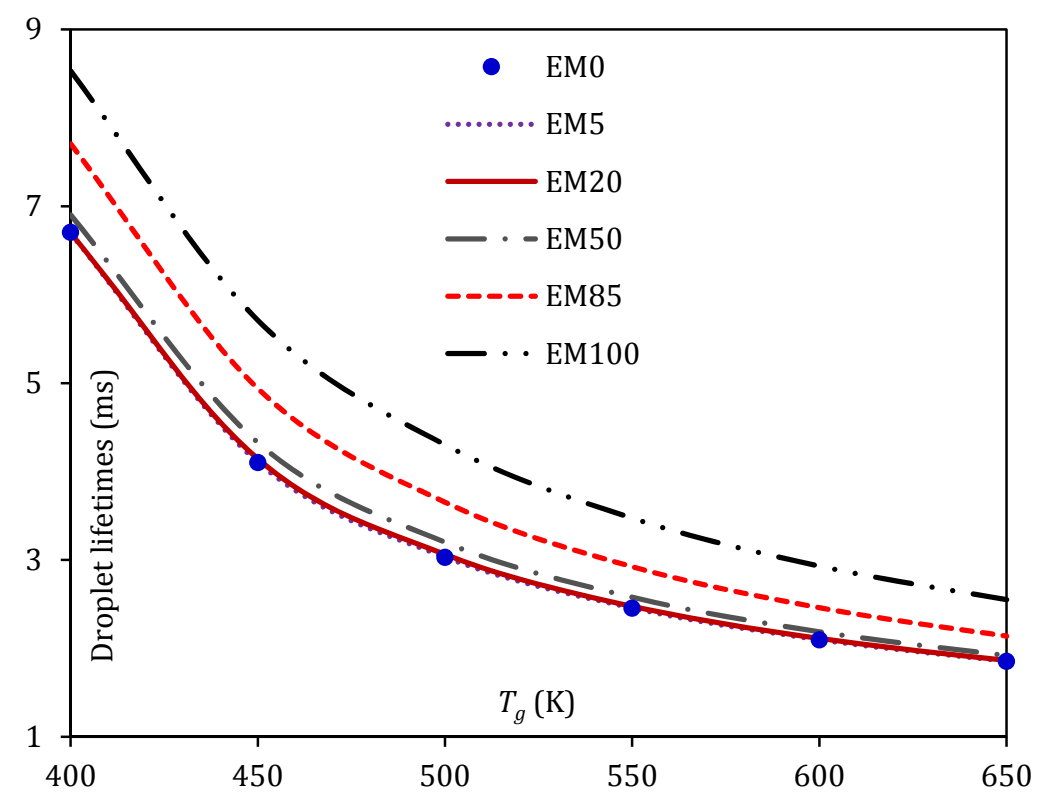

Figure 7. The effect of ambient temperatures on droplet lifetimes for EM0-EM100 fuel blends, estimated at ambient pressure 3 bar, using the DC model and the same other input parameters as in Figures 2-6. The effects of thermal radiation are ignored. 


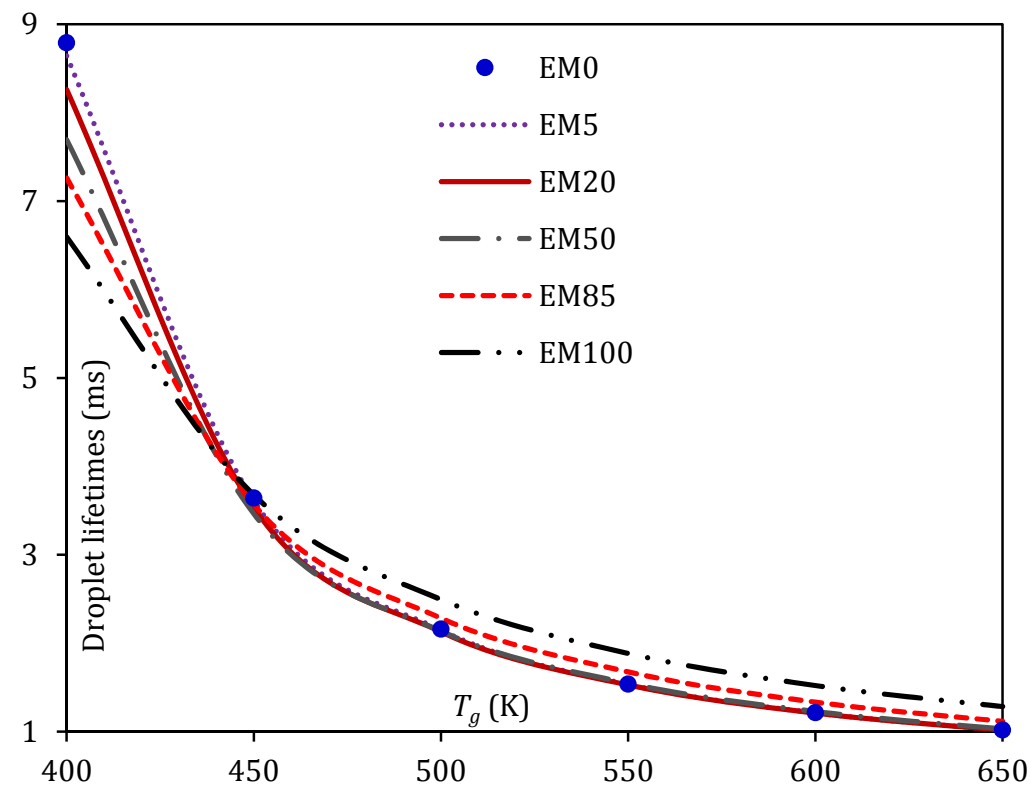

Figure 8. The effect of ambient temperatures on droplet lifetimes for EM0-EM100 fuel blends, estimated at ambient pressure 30 bar, using the DC model and the same other input parameters as in Figures 2-7. The effects of thermal radiation are ignored.

As can be seen in Figure 7, at a relatively low ambient pressure (3 bar), increasing the ambient temperature noticeably reduces droplet lifetime. This effect becomes more significant at higher ambient pressure (30 bar), as shown in Figure 8. To summarise, increasing radiative temperature, ambient pressure, or ambient temperature, always leads to a faster evaporation of ethanol/gasoline droplets, regardless of their blending fractions.

In Figures 2 and 5-8, the general trends indicate slower evaporation for ethanol (EM100) droplets than for gasoline and gasoline blend droplets (EM0-EM85). However, these trends are not the same at relatively low ambient gas temperatures $(\leq 400 \mathrm{~K})$, as can be seen from Figure 8. At these temperatures, as follows from the latter figure, EM100 droplet evaporation can become slightly faster than that of EM0-EM85 droplets. The droplet lifetimes versus gas pressure for all mixtures under consideration for ambient gas temperature $400 \mathrm{~K}$ are presented in Figure 9. 


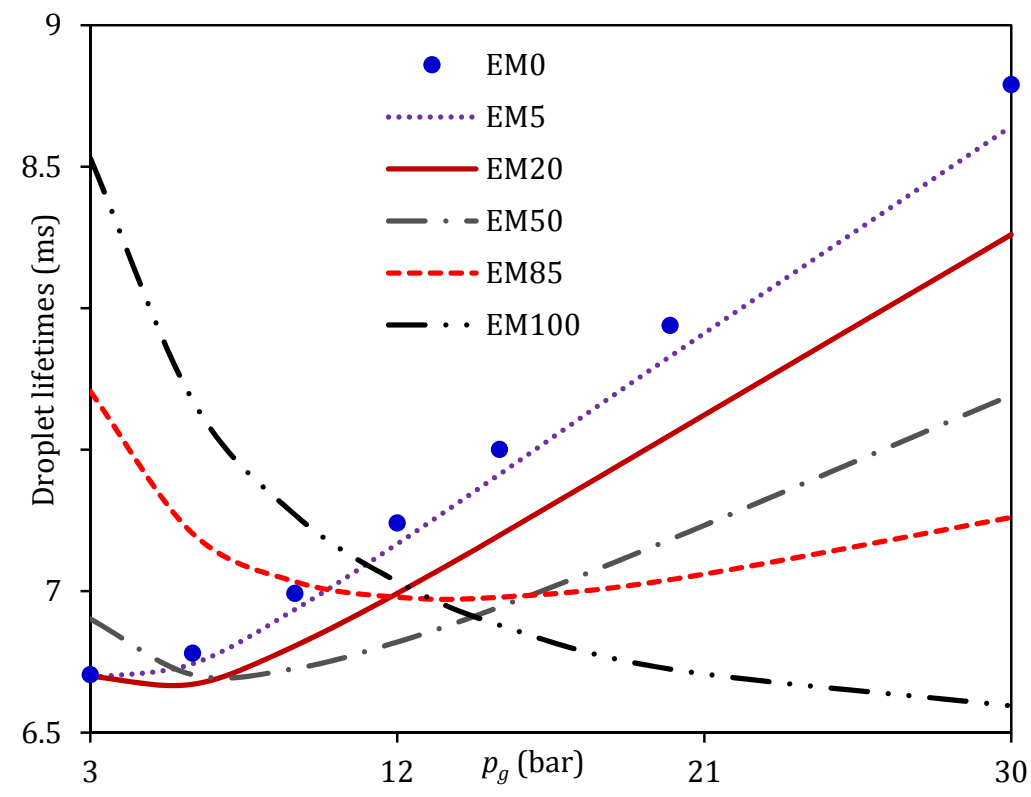

Figure 9. The effect of ambient pressures on droplet lifetimes for EM0-EM100 fuel blends, estimated at ambient temperature 400K, using the DC model and the same other input parameters as in Figures 2-8.

As can be seen in Figure 9, ambient pressures have a different effect on the lifetimes of EM0-EM100 droplets to those shown in Figures 6-8 for the same fuels, but at higher ambient temperatures $(>400 \mathrm{~K})$. The uncommon in-cylinder conditions, relatively low ambient temperatures $(\leq 400 \mathrm{~K})$ and high ambient pressures ( $\geq 12$ bar), lead to lower droplet lifetimes for EM100 than for E0. This can be attributed to the different responses of the thermodynamic and transport properties of these fuels under these unique ambient conditions.

\section{Conclusions}

The impacts of ambient conditions - including pressure and ambient and radiative temperatures, and fractions of ethanol in ethanol/gasoline fuel blends - on droplet heating and evaporation are investigated. The Discrete Component (DC) model is used for the analysis. The full composition of gasoline FACE C fuel, transient diffusion of species, recirculation, and temperature gradient inside droplets are accounted for, using the Effective Thermal Conductivity/Effective Diffusivity (ETC/ED) model. The model is validated against relevant experimental data.

The analysis focuses on fuel blends with $0 \%, 5 \%, 20 \%, 50 \%, 85 \%$ and $100 \%$ molar fractions of ethanol, and it is shown that the droplet lifetime for pure gasoline fuel is the smallest, but its maximal droplet surface temperature is the largest. The droplet lifetime increases with increasing ethanol molar fraction, leading to a difference of $33.9 \%$ between pure gasoline fuel and pure ethanol results under the same conditions. Also, the predicted ethanol droplet surface temperature is shown to be up to $24.3 \%$ higher than that predicted for gasoline fuel. This is attributed to the fact that ethanol has lower boiling and critical temperatures, but higher liquid density and vapour saturation pressure than gasoline fuel. 
It is concluded that the addition of ethanol to gasoline fuel makes the fuel less volatile. Increasing the radiative temperature, ambient pressure, or ambient temperature, leads to a faster evaporation of ethanol/gasoline droplets regardless of their blending fractions at temperatures greater than $400 \mathrm{~K}$. At low ambient temperature $(400 \mathrm{~K})$, however, increasing the ambient pressure leads to longer droplet lifetimes.

\section{Acknowledgments}

The authors are grateful to Dr S. Corsetti of Dundee University for providing the experimental data, Dr A. Bader of the Technical University Bergakademie Freiberg for useful discussion, and Dr 0. Rybdylova of Brighton University for drawing their attention to erroneous formulae given in. ${ }^{26,37}$ The Centre for Mobility and Transport, Coventry University, is acknowledged for providing financial support for the work on this project. One of the authors (S.S. Sazhin) is grateful to EPSRC (grant EP/M002608/1) for their financial support. 


\section{Appendix A. Gasoline saturated vapour pressure}

The following expression, inferred from, ${ }^{28,38}$ is used in our model:

$\ln p_{r}^{\text {sat }}=f^{0}\left(T_{r}\right)+\omega f^{1}\left(T_{r}\right)+\omega^{2} f^{2}\left(T_{r}\right)$,

where

$\omega=-\frac{\ln \frac{P_{c}}{1.01325}+f^{o}\left(T_{b r}\right)}{f^{1}\left(T_{b r}\right)}$

$f^{o}\left(T_{r}\right)=\left(-5.97616 \tau+1.29874 \tau^{1.5}-0.60394 \tau^{2.5}-1.06841 \tau^{5}\right) / T_{r}$,

$f^{1}\left(T_{r}\right)=\left(-5.03365 \tau+1.11505 \tau^{1.5}-5.41217 \tau^{2.5}-7.46628 \tau^{5}\right) / T_{r}$,

$f^{2}\left(T_{r}\right)=\left(-0.64771 \tau+2.41539 \tau^{1.5}-4.26979 \tau^{2.5}+3.25259 \tau^{5}\right) / T_{r}$,

$\tau=1-T$.

Note that there was a mistake in the corresponding expression for $p_{r}^{\text {sat }}$, given in, ${ }^{37}$ which was overlooked in. ${ }^{26}$ For the range of temperatures used in our model $(296-484 \mathrm{~K})$, the error in the estimated pressure calculation in ${ }^{37}$ could lead to overprediction of the droplet evaporation time by up to $150 \%$.

\section{Appendix B. Thermodynamic and transport properties of ethanol}

\section{B.1 Boiling and critical points and liquid density}

The boiling temperature, critical temperature, and critical pressure of ethanol $\left(\mathrm{C}_{2} \mathrm{H}_{6} \mathrm{O}\right)$ are $351.44 \mathrm{~K}, 516.25$ $\mathrm{K}$ and 63.84 bar, respectively. ${ }^{29}$ The following expression for the liquid density of ethanol has been used in our analysis: ${ }^{29}$

$\rho=1000 A B^{-\left(1-T_{r}\right)^{C}}\left(\mathrm{~kg} \mathrm{~m}^{-3}\right)$,

where $A=0.2657, B=0.264$ and $C=0.2367$. The results predicted by Equation (12) have been compared with approximations suggested in ${ }^{32,33}$ and validated against experimental data provided in, 39 as shown in Figure B.1. 


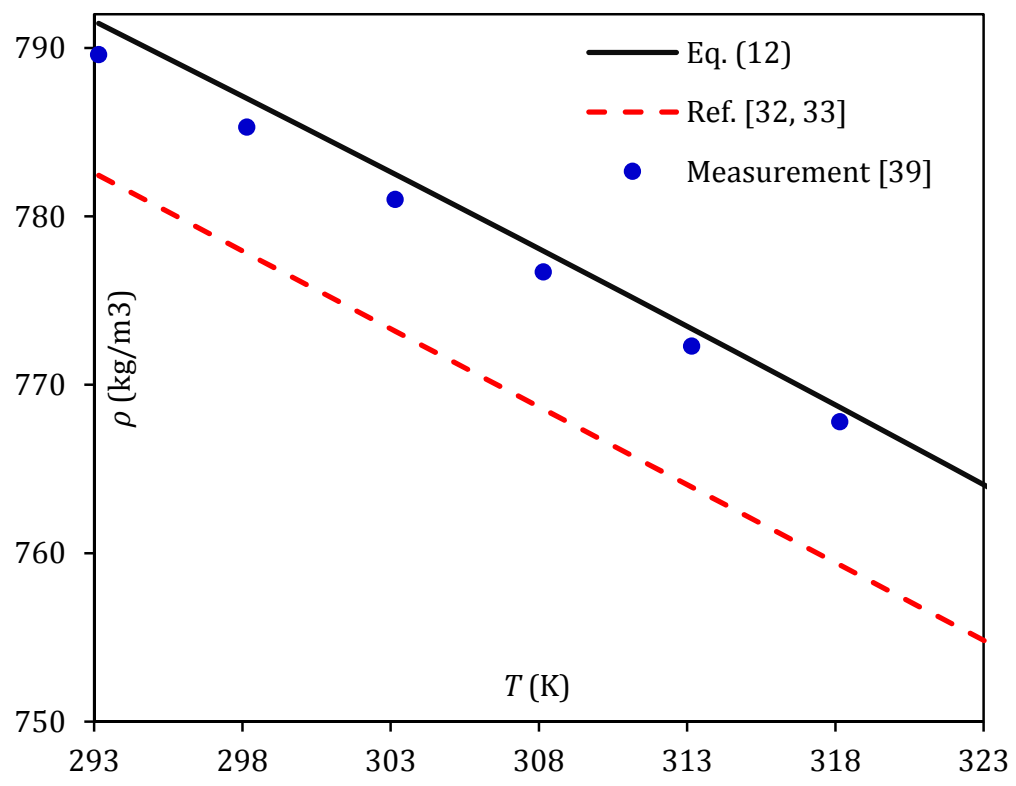

Figure B.1. Comparison of liquid density $(\rho)$ estimated using Equation (12) with other approximations and experimental data reported in the literature.

\section{B.2 Liquid viscosity}

The following approximation for the liquid viscosity of ethanol is used in our analysis: ${ }^{32,33}$

$\log _{10} \mu=\frac{686.64}{T}-5.282$ (Pa.s).

The results predicted by Equation (13) were compared with those inferred from ${ }^{29,40}$ and experimental data provided in, ${ }^{41}$ as shown in Figure B.2.

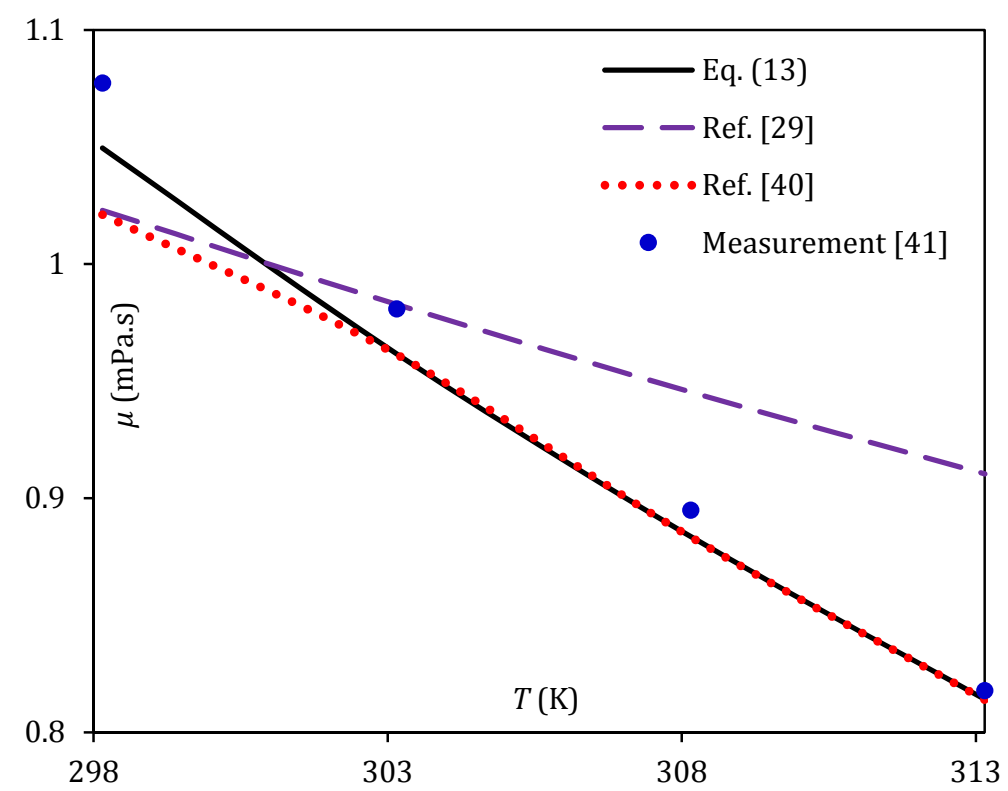

Figure B.2. Comparison of liquid viscosity $(\mu)$, estimated using Equation (13), with other approximations and experimental data reported in the literature.

\section{B.3 Liquid heat capacity}

The specific heat capacity was calculated using the following approximation: ${ }^{42}$ 
$C_{P}=\left(A+B T+C T^{2}+D T^{3}\right) / M_{w t}\left(\mathrm{~J} k g^{-1} \mathrm{~K}^{-1}\right)$,

where $A=102640, B=-139.63, C=-0.03034$ and $D=0.0020386$. Predictions of Equation (14) were compared with the approximations suggested in, ${ }^{29,32,33}$ and validated against experimental data provided in. ${ }^{39}$ The results are shown in Figure B.3.

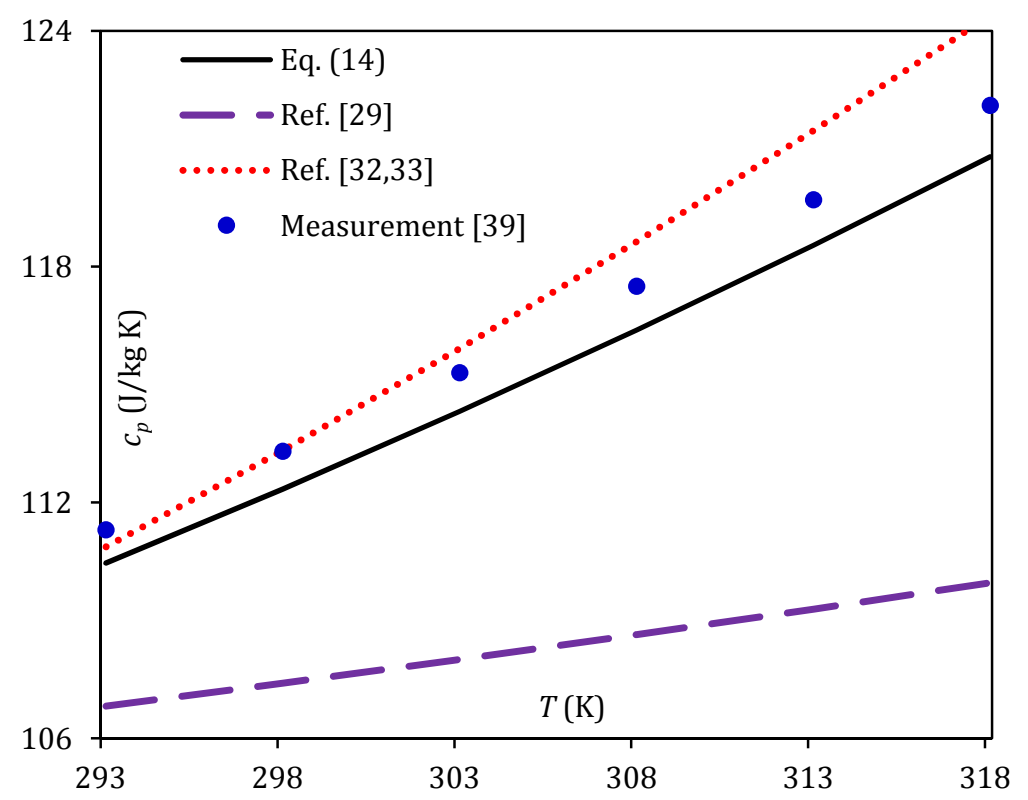

Figure B.3. Comparison of specific liquid heat capacity $\left(c_{p}\right)$, predicted by Equation (14), with other approximations and experimental data reported in. ${ }^{39}$

\section{B.4 Saturated vapour pressure}

The saturated vapour pressure was estimated using the following approximation:32,33,40

$\ln \left(\frac{p^{\text {sat }}}{133.3224}\right)=A-B /(C+T) \quad(\mathrm{Pa})$

where $A=18.5242, B=3578.91$ and $C=50.5$. The predictions of Equation (15) were compared with the approximations suggested in ${ }^{28,29}$ and experimental data provided in. ${ }^{43}$ The results are shown in Figure B.4. 


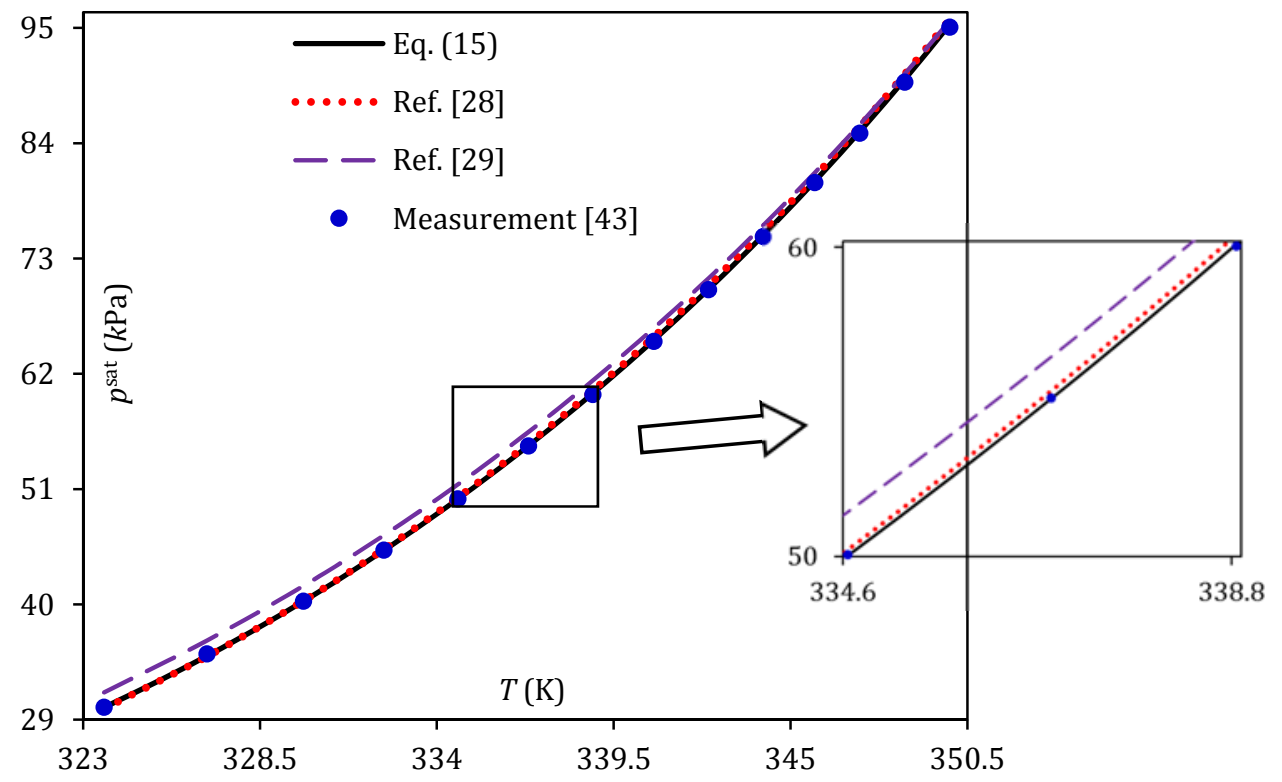

Figure B.4. Comparison of saturated vapour pressure $\left(p^{\text {sat }}\right)$, predicted by Equation (15), with other approximations and experimental data reported in. ${ }^{43}$

\section{B.5 Latent heat of evaporation}

Latent heat of evaporation was estimated using the following approximation:32,33

$L=120910\left(T_{C T}-T\right)^{0.38}\left(\mathrm{~J} \mathrm{~kg}^{-1}\right)$,

The predictions of Equation (16) were compared with the approximation suggested in ${ }^{29}$ and experimental data provided in. ${ }^{44}$ The results of this comparison are shown in Figure B.5.

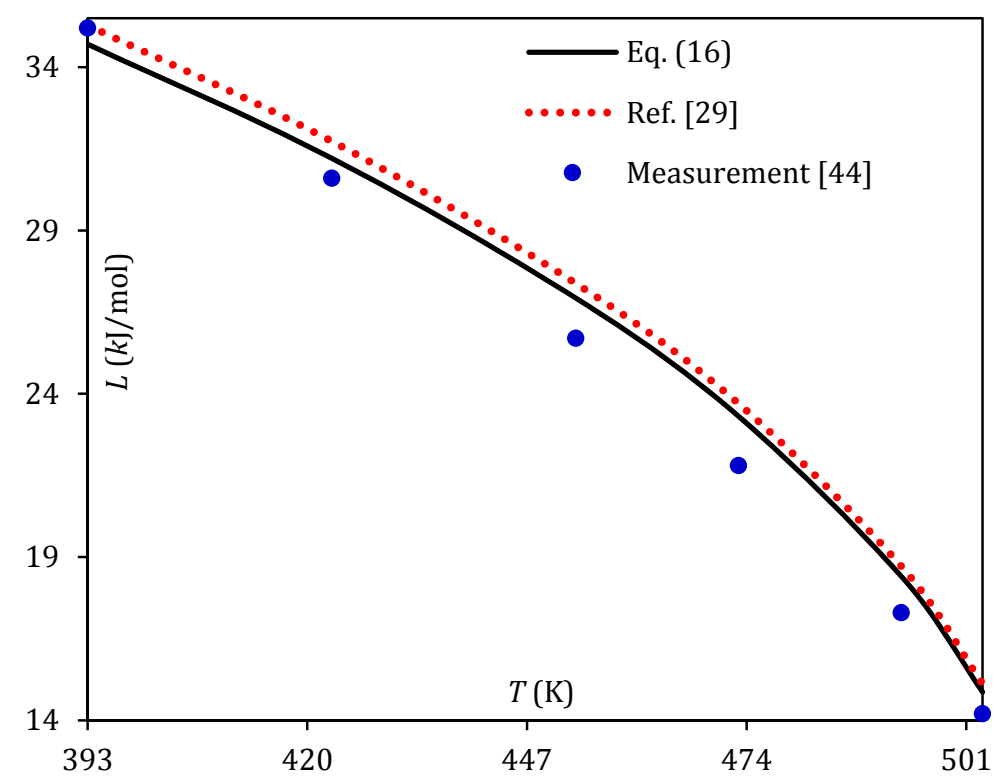

Figure B.5. Comparison of the latent heat of evaporation $(L)$ inferred from Equation (16) with other approximations and experimental data.

\section{B.6 Liquid thermal conductivity}

Liquid thermal conductivity was estimated using the following approximation: ${ }^{29}$ 
$k=A+B T+C T^{2}\left(\mathrm{~W} \mathrm{~m}^{-1} \mathrm{~K}^{-1}\right)$,

where $A=0.2245, B=-0.00005633$ and $C=-0.00000042178$. The results predicted by Equation (17) were compared with the estimations of thermal conductivity reported by other authors $32,33,42$ and experimental data reported in. ${ }^{45}$ The results of this comparison are shown in Figure B.6.

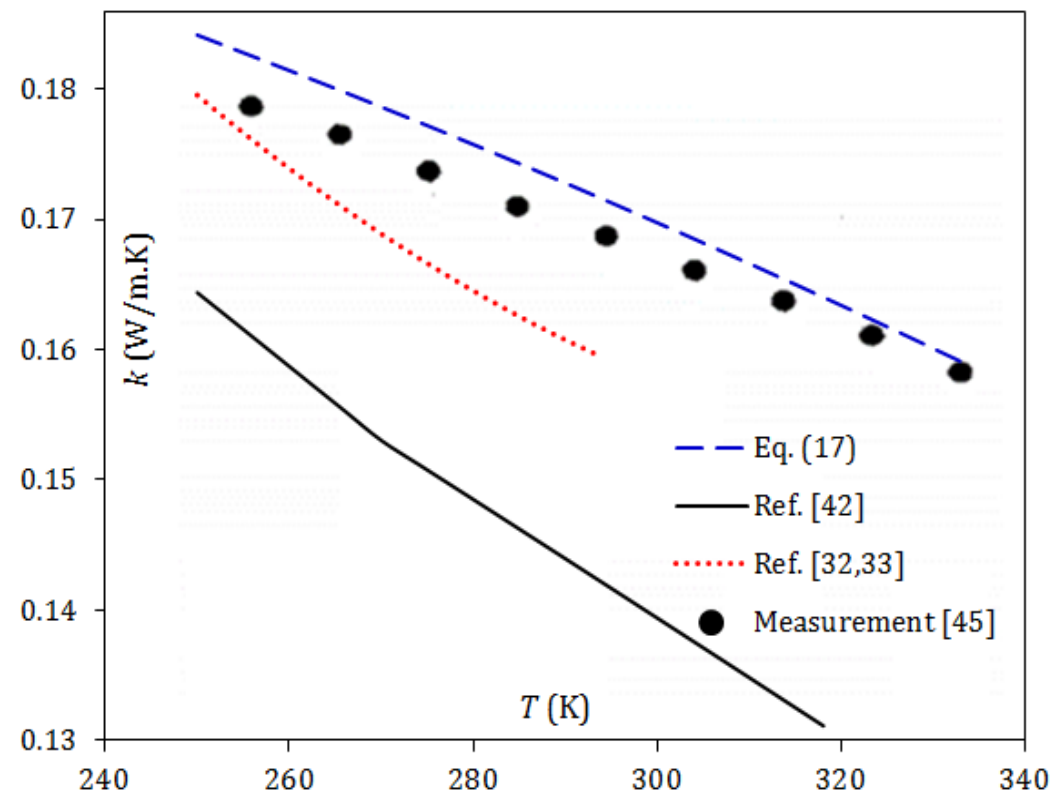

Figure B.6. Comparison of the liquid thermal conductivity estimated using Equation (17) with other approximations and experimental data. 


\section{Appendix C. Effects of thermal radiation}

The impact of radiation on the estimated radii and temperatures of EM0-EM100 droplets is shown in Figure C.1.
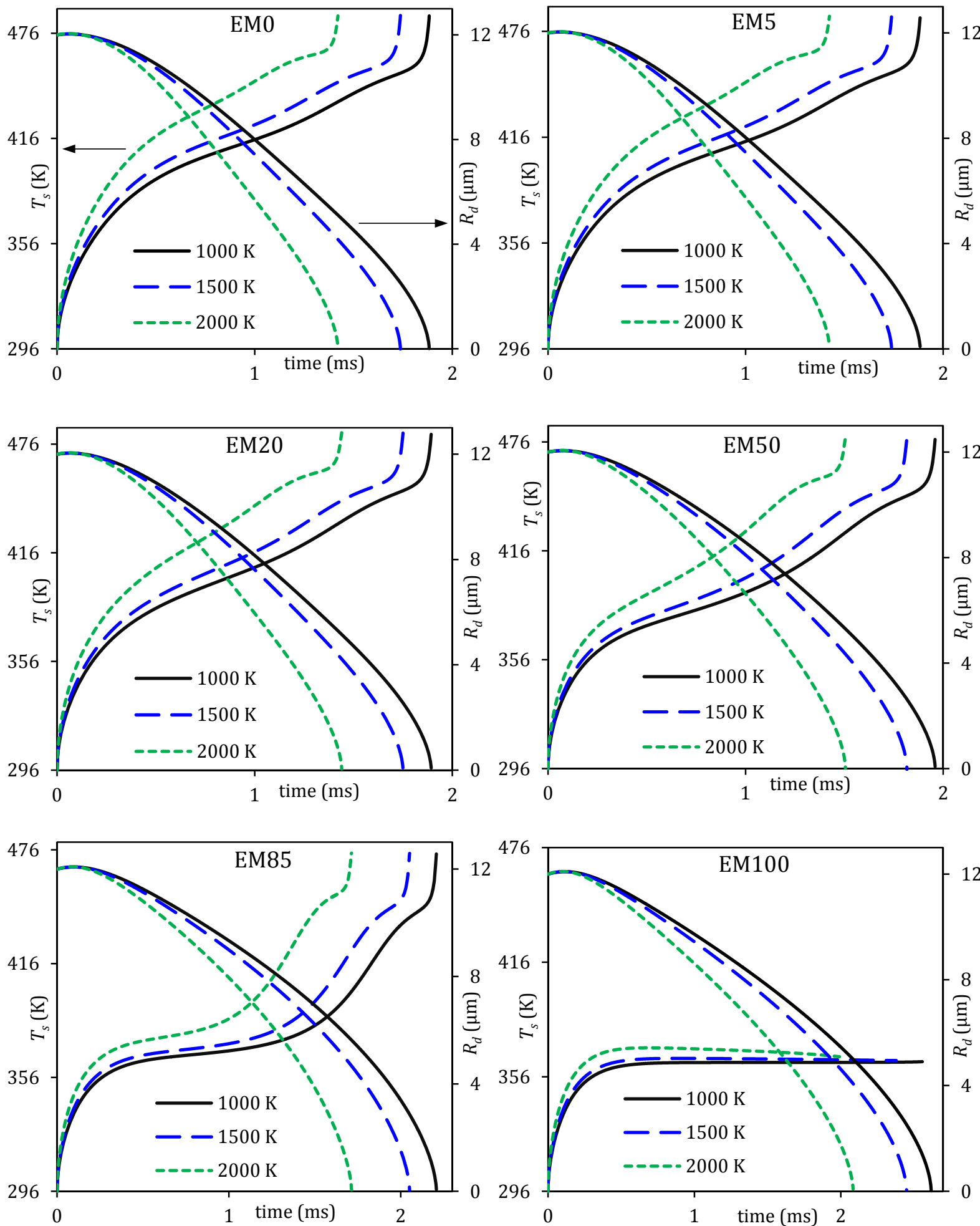

Figure C.1. Effects of radiative temperatures $(1000 \mathrm{~K}, 1500 \mathrm{~K}$, and $2000 \mathrm{~K})$ on droplet radii and surface temperatures for EM0, EM5, EM20, EM50, EM85 and EM100 blends, using the same ambient conditions and input parameters as in Figures 2-9. 


\section{References}

(1) Járvás, G.; Kontos, J.; Hancsók, J.; Dallos, A. Int. J. Heat Mass Transf. 2015, 84, 1019-1029.

(2) Bader, A.; Keller, P.; Hasse, C. Int. J. Heat Mass Transf. 2013, 64, 547-558.

(3) Corsetti, S.; Miles, R. E. H.; McDonald, C.; Belotti, Y.; Reid, J. P.; Kiefer, J.; McGloin, D. J. Phys. Chem. A 2015, 119 (51), 12797-12804.

(4) EPA, U. US Environmental Protection Agency http://www.epa.gov/ (accessed Jun 23, 2017).

(5) Masum, B. M.; Masjuki, H. H.; Kalam, M. A.; Rizwanul Fattah, I. M.; Palash, S. M.; Abedin, M. J. Renew. Sustain. Energy Rev. 2013, 24, 209-222.

(6) US Department of Energy: Energy Efficiency and Renewable Energy. Alternative Fuels Data Centre http://www.afdc.energy.gov (accessed Jun 23, 2017).

(7) Banerjee, R. Fuel 2013, 107, 724-739.

(8) Su, M.; Chen, C. P. Fuel 2015, 161, 215-221.

(9) Ma, X.; Jiang, C.; Xu, H.; Ding, H.; Shuai, S. Fuel 2014, 116, 281-291.

(10) Paxson, F. L. The last American frontier; Simon Publications LLC, 2001.

(11) Sazhin, S. S.; Kristyadi, T.; Abdelghaffar, W. A.; Begg, S.; Heikal, M. R.; Mikhalovsky, S. V.; Meikle, S. T.; Al-Hanbali, O. J. Heat Transf. 2007, 129 (9), 1246.

(12) Pitz, W. J.; Cernansky, N. P.; Dryer, F. L.; Egolfopoulos, F. N.; Farrell, J. T.; Friend, D. G.; Pitsch, H. Development of an Experimental Database and Chemical Kinetic Models for Surrogate Gasoline Fuels; SAE Technical Paper 2007-1175; SAE International: Warrendale, PA, 2007.

(13) Sazhin, S. S. Prog. Energy Combust. Sci. 2006, 32 (2), 162-214.

(14) Sazhin, S. S.; Elwardany, A.; Krutitskii, P. A.; Castanet, G.; Lemoine, F.; Sazhina, E. M.; Heikal, M. R. Int. J. Heat Mass Transf. 2010, 53 (21-22), 4495-4505.

(15) Sazhin, S. S. Droplets and Sprays; Springer: London, 2014.

(16) Sazhin, S. S. Fuel 2017, 196, 69-101.

(17) Elwardany, A. E.; Gusev, I. G.; Castanet, G.; Lemoine, F.; Sazhin, S. S. Atom. Sprays 2011, 21 (11), $907-931$.

(18) Sazhin, S. S.; Al Qubeissi, M.; Kolodnytska, R.; Elwardany, A. E.; Nasiri, R.; Heikal, M. R. Fuel 2014, 115, 559-572.

(19) Sazhin, S. S.; Al Qubeissi, M.; Nasiri, R.; Gun'ko, V. M.; Elwardany, A. E.; Lemoine, F.; Grisch, F.; Heikal, M. R. Fuel 2014, 129, 238-266.

(20) Zhu, G.-S.; Reitz, R. D. Int. J. Heat Mass Transf. 2002, 45 (3), 495-507.

(21) Laurent, C.; Lavergne, G.; Villedieu, P. Comptes Rendus Mécanique 2009, 337 (6-7), 449-457.

(22) Grote, M.; Lucka, K.; Köhne, H. In V ECCOMAS CFD; Lisbon, Portugal, 2010.

(23) Burger, M.; Schmehl, R.; Prommersberger, K.; Schäfer, O.; Koch, R.; Wittig, S. Int. J. Heat Mass Transf. 2003,46 (23), 4403-4412.

(24) Smith, B. L.; Bruno, T. J. Int. J. Thermophys. 2006, 27 (5), 1419-1434.

(25) Qi, D. H.; Lee, C. F. J. Taiwan Inst. Chem. Eng. 2014, 45 (2), 504-507.

(26) Al Qubeissi, M.; Sazhin, S. S.; Turner, J.; Begg, S.; Crua, C.; Heikal, M. R. Fuel 2015, 159, 373-384.

(27) Rybdylova, O.; Poulton, L.; Al Qubeissi, M.; Elwardany, A. E.; Crua, C.; Khan, T.; Sazhin, S. S. Int. Commun. Heat Mass Transf. 2018, 90, 29-33.

(28) Poling, B. E.; Prausnitz, J. M.; O'Connell, J. P. The properties of gases and liquids; McGraw-Hill: New York, 2001.

(29) Yaws, C. L. The Yaws handbook of vapor pressure: Antoine coefficients; Gulf Pub.: Houston, Tex., 2007.

(30) Al Qubeissi, M.; Sazhin, S. S.; Elwardany, A. E. Fuel 2017, 187, 349-355.

(31) Dooley, S.; Uddi, M.; Won, S. H.; Dryer, F. L.; Ju, Y. Combust. Flame 2012, 159 (4), 1371-1384.

(32) Elwardany, A. E. Modelling of multi-component fuel droplets heating and evaporation. PhD thesis, University of Brighton: UK, 2012.

(33) Deprédurand, V. Approche expérimentale de l'évaporation de sprays de combustibles multicomposant; Vandoeuvre-les-Nancy, INPL, 2009.

(34) Rybdylova, O.; Qubeissi, M. A.; Braun, M.; Crua, C.; Manin, J.; Pickett, L. M.; Sercey, G. de; Sazhina, E. M.; Sazhin, S. S.; Heikal, M. Int. Commun. Heat Mass Transf. 2016.

(35) Sazhin, S. S.; Krutitskii, P. A.; Abdelghaffar, W. A.; Sazhina, E. M.; Mikhalovsky, S. V.; Meikle, S. T.; Heikal, M. R. Int. J. Heat Mass Transf. 2004, 47 (14-16), 3327-3340.

(36) Abramzon, B.; Sazhin, S. S. Fuel 2006, 85 (1), 32-46.

(37) Komkoua Mbienda, A. J.; Tchawoua, C.; Vondou, D. A.; Mkankam Kamga, F. Int. J. Geophys. 2013, 2013 , e612375.

(38) Reid, R. C.; Prausnitz, J. M.; Sherwood, T. K. The properties of gases and liquids, 3d ed.; McGraw-Hill chemical engineering series; McGraw-Hill: New York, 1977.

(39) García-Miaja, G.; Troncoso, J.; Romaní, L. Fluid Phase Equilibria 2008, 274 (1-2), 59-67.

(40) Sinnott, R. K. Chemical Engineering Design, 4th ed.; Elsevier Butterworth-Heinemann: Oxford, 2005.

(41) Sih, R.; Armenti, M.; Mammucari, R.; Dehghani, F.; Foster, N. R. J. Supercrit. Fluids 2008, 43 (3), 460-468.

(42) Perry, R. H. Perry's Chemical Engineers' Handbook, 7th ed.; McGraw-Hill, 1997.

(43) Aucejo, A.; Loras, S.; Muñoz, R.; Ordoñez, L. M. Fluid Phase Equilibria 1999, 156 (1-2), 173-183.

(44) NIST http://webbook.nist.gov/chemistry/fluid/ (accessed Jul 28, 2017).

(45) Petravic, J.J. Chem. Phys. 2005, 123 (17), 174503. 